\title{
Investigating microbial transformations of soil organic matter: synthesizing knowledge from disparate fields to guide new experimentation
}

\author{
S. A. Billings ${ }^{1}$, L. K. Tiemann ${ }^{2}$, F. Ballantyne IV ${ }^{3}$, C. A. Lehmeier ${ }^{1}$, and K. Min ${ }^{1}$ \\ ${ }^{1}$ Department of Ecology and Evolutionary Biology and the Kansas Biological Survey, \\ University of Kansas, Lawrence, KS, USA \\ ${ }^{2}$ Department of Plant, Soil, and Microbial Sciences, Michigan State University, East Lansing, MI, USA \\ ${ }^{3}$ Odum School of Ecology, University of Georgia, Athens, GA, USA \\ Correspondence to: S. A. Billings (sharon.billings@ku.edu)
}

Received: 30 October 2014 - Published in SOIL Discuss.: 3 December 2014

Revised: - - Accepted: 15 March 2015 - Published: 9 April 2015

\begin{abstract}
Discerning why some soil organic matter (SOM) leaves soil profiles relatively quickly while other compounds, especially at depth, can be retained for decades to millennia is challenging for a multitude of reasons. Simultaneous with soil-specific advances, multiple other disciplines have enhanced their knowledge bases in ways potentially useful for future investigations of SOM decay. In this article, we highlight observations highly relevant for those investigating SOM decay and retention but often emanating from disparate fields and residing in literature seldom cited in SOM research. We focus on recent work in two key areas. First, we turn to experimental approaches using natural and artificial aquatic environments to investigate patterns of microbially mediated OM transformations as environmental conditions change, and highlight how aquatic microbial responses to environmental change can reveal processes likely important to OM decay and retention in soils. Second, we emphasize the importance of establishing intrinsic patterns of decay kinetics for purified substrates commonly found in soils to develop baseline rates. These decay kinetics - which represent the upper limit of the reaction rates - can then be compared to substrate decay kinetics observed in natural samples, which integrate intrinsic decay reaction rates and edaphic factors essential to the site under study but absent in purified systems. That comparison permits the site-specific factors to be parsed from the fundamental decay kinetics, an important advance in our understanding of SOM decay (and thus persistence) in natural systems. We then suggest ways in which empirical observations from aquatic systems and purified substrate-enzyme reaction kinetics can be used to advance recent theoretical efforts in SOM-focused research. Finally, we suggest how the observations in aquatic and purified substrate-enzyme systems could be used to help unravel the puzzles presented by oft-observed patterns of SOM characteristics with depth, as one example of the many perplexing SOM-related problems.
\end{abstract}

\section{Introduction}

In spite of a multitude of studies exploring the drivers of soil organic matter (SOM) decay, investigators still struggle with a deceptively simple-sounding question: why does some SOM leave the soil profile relatively quickly, while other compounds, especially those at depth, appear to be retained on timescales ranging from the decadal to the millennial?
This question is important on a practical as well as academic level: understanding SOM retention over long time periods helps us predict soil fluxes of carbon (C) and thus Earth's atmospheric $\mathrm{CO}_{2}$, as well as fundamental features of ecosystem metabolism. However, addressing this question is challenging for a multitude of reasons. Most of the biogeochemical tools employed by those investigating SOM decay capture data of a very integrated nature, as they are influenced 
by many processes. As a result, such data are difficult to interpret. Respired $\mathrm{CO}_{2}$, activity levels of exo-enzymes exuded by microbes, and changing availability of dissolved organic carbon (DOC), for example, integrate fluxes driven by the metabolically active subset of the whole living microbial community in a soil sample, but how the active subset fits into the context of the greater community is not known. Furthermore, the organic substrates that the active subset transforms into energy, biomass, exo-enzymes, or waste are typically of unknown identity. Of key interest for many scientists is how these fluxes (and hence the size of the pools those fluxes drain or augment) are modified with environmental factors such as temperature or moisture. Such knowledge remains elusive while we still struggle with attempts to measure and understand these processes in relatively stable environments. Further complicating our efforts, soil profiles are heterogeneous environments. Physical and chemical protection of SOM and microbial community composition varies across spatial scales ranging from the molecular to the continental (Schimel and Schaeffer, 2012). Thus, one soil sample's SOM decay response to an environmental perturbation may not hold true for samples collected in close proximity, much less for different depths at the same location, or for soil types in distinct climate regimes.

Concerns about SOM destabilization with climate change have generated increased urgency within the discipline in recent decades (Kirschbaum, 1995; Bradford, 2013; Billings and Ballantyne, 2013). Soil-focused literature is now replete with papers empirically describing temperature, moisture, or nutrient concentration effects on different SOM decay processes (e.g., Craine et al., 2010; Wagai et al., 2013; Manzoni et al., 2012b; Tiemann and Billings, 2011a; Moyano et al., 2013). From these and related efforts, we have gained an appreciation for the apparent relevance of the carbon (C) quality hypothesis, which states that slowly decomposing SOM is more sensitive, in a relative sense, to temperature changes than SOM that decays more quickly (Bosatta and Ågren, 1999). However, this response is not evident in some soils (Laganiere et al., 2015). We also have learned that historic conditions serve as a meaningful driver of contemporary biogeochemical responses to varying conditions in soils (Evans and Wallenstein, 2012). We have appreciated the tremendous diversity of soil microbial communities and their rapidly varying composition as environmental conditions vary (Howe et al., 2014; Billings and Tiemann, 2014). There is growing recognition of an apparent lack of inherent recalcitrance of many SOM pools previously thought to be relatively stable, particularly those at depth (Fontaine et al., 2007; Schmidt et al., 2011), prompting considerations that temperature sensitivity may not vary with depth as much as previously thought. Recent modeling efforts, particularly those focusing on temperature and nutrient availability as drivers of microbial behavior, also have enhanced our ability to identify key factors important to SOM fate in a changing environment (e.g., Manzoni et al., 2012a).
Simultaneous with these soil-specific advances, other disciplines have enhanced their knowledge bases in ways potentially useful for future investigations of SOM decay. However, results of these efforts are reported in a widely dispersed literature often not frequented by the SOM-focused community of scholars. For example, microbiologists have demonstrated that gene expression by heterotrophic bacteria in the oceans can exhibit diurnal fluctuations (Ottesen et al., 2014). Such work highlights linkages between heterotrophic activity and short-term fluctuations in resource availability, a topic of central importance to OM decay. Though some of the principles of OM decay in ocean systems clearly are relevant to soils (Jiao et al., 2010), studies describing oceanic OM transformations are rarely cited in the soil literature. Also rarely invoked by soil biogeochemists are laboratory experiments that study soil-relevant processes using reductionist approaches. For example, chemostat experiments are ideally suited to study fundamental physiological functioning of microbes and can provide empirical data relevant to recent advances in ecological stoichiometric theory (Elser et al., 2000; Manzoni et al., 2012a). However, the relative paucity of linkages across disciplines exploring aquatic and terrestrial $\mathrm{OM}$ and microbiology makes it challenging to apply such results in a broader, ecological context.

In this article, we highlight observations highly relevant for those investigating SOM decay and retention but often emanating from disparate fields and residing in literature seldom cited in SOM research papers. We focus on recent work in two key areas. First, we turn to experimental approaches using natural and artificial aquatic environments to investigate patterns of microbially mediated OM transformations as environmental conditions change. In 1997, John Hedges and John Oades made an elegant plea for investigators of OM decay in soils and aquatic environments to integrate their approaches and ideas to elucidate patterns and mechanisms common to both systems (Hedges and Oades, 1997). We echo this call by highlighting how some of the microbial responses to environmental change in aquatic environments can reveal processes likely important to OM decay and retention in soils. Second, we emphasize the importance of establishing intrinsic patterns of decay kinetics for purified substrates commonly found in soils to develop baseline rates. These decay kinetics can then be compared to substrate decay kinetics observed in natural samples, which integrate intrinsic decay reaction rates and edaphic factors essential to the site under study but absent in purified systems. That comparison permits the site-specific factors to be parsed from the fundamental decay kinetics, an important advance in our understanding of SOM decay (and thus persistence) in natural systems. We then suggest ways in which empirical observations from aquatic systems and purified substrate-enzyme reaction kinetics can be used to advance recent theoretical efforts in SOM-focused research. Finally, we suggest how the observations in aquatic and purified substrate-enzyme systems could be used to help unravel the puzzles presented by 
oft-observed patterns of SOM characteristics with depth, as one example of the many perplexing SOM-related problems.

\section{Using well-mixed natural and artificial systems to avoid challenges present in soils}

One potential means of addressing some of the challenges in SOM research described above is to investigate the decay of organic substrates in the absence of soils. Much ocean and freshwater OM decay proceeds via the same fundamental processes present in soil, via microbially produced exoenzymes, and can be restricted via some of the same processes as well. For example, aggregate formation can protect ocean OM from decay (Jiao et al., 2010), much as it does in soils (Six and Paustian, 2013). As such, invoking knowledge derived from ocean and freshwater systems about the microbial processes relevant to aquatic OM decay, where substrate and enzymatic diffusion is far less limiting than in typical soil profiles, can provide valuable insight into the microbial processes driving SOM decay or retention.

Artificial aquatic systems in which environmental conditions and resident microbes can be strictly controlled are also useful for those investigating SOM decay and retention. Such systems represent conditions far removed from soil profiles, and at first glance appear foreign to SOM studies. Chemostats are well suited to support one, isolated microbial population (Monod, 1950), in sharp contrast with the complex communities found in natural systems. Chemostats also typically present the microorganisms they support with a constant substrate supply, and are subjected to manipulation of just one environmental parameter (Ferenci, 2008). As a result, we probably cannot consider absolute values of the size or composition of any resource pool or flux observed during such experiments as immediately comparable to those that would occur in soils. However, by largely relieving diffusional constraints on organic substrates, exo-enzymes, mineral nutrients, and the microorganisms themselves, chemostat environments mitigate at least one concern present in soil research: that results are relevant only for one particular soil profile due to heterogeneous conditions. Furthermore, experiments in artificial aquatic environments can offer proof of concept for physiological responses of microbes to a varying environment (e.g., changing temperature or nutrient availability), and as such provide those who venture into natural soil environments with information about fundamental, baseline responses of microbes to changing conditions. That information, in turn, can provide a starting point for formulating predictions about how soil microorganisms may respond to environmental change.

By turning to natural and artificial aquatic systems for guidance, we do not mean to imply that diffusional constraints are not important. Indeed, they may be the prominent feature driving SOM decay in many soils (Dungait et al., 2012). However, by studying aquatic systems we gain insight into enzymatic and microbial responses to changing environmental conditions in relative isolation from such constraints, and that in turn allows us to assess the relative importance of the very constraints we have eliminated. In the following sections, we present advances from natural and artificial environments relevant to research on microbially mediated SOM transformations, beginning with oceanic and lacustrine systems and then examining increasingly controlled environments.

\subsection{Natural aquatic systems as well-mixed environments in which to explore drivers of $C$ fluxes and microbial elemental composition}

Investigations of microbial transformations of $\mathrm{OM}$ in the oceans provide important information for those interested in understanding SOM dynamics. For example, organic geochemists working in the ocean have appreciated the role of the "microbial loop" as a governing feature of ocean OM composition and availability for decades (Pomeroy, 1974; Azam et al., 1983; Pomeroy et al., 2007). Work in ocean waters has demonstrated the importance of microbial byproducts as contributors to the ocean's reservoirs of OM (Kawasaki and Benner, 2006; Kaiser and Benner, 2008) and, more specifically, to the ocean's slow-turnover OM pools (Jiao et al., 2010). The call made by Hedges and Oades (1997) to integrate aquatic and terrestrial studies is slowly being heeded, as reflected in the soil literature acknowledging the important role microorganisms appear to play as producers, not just consumers, of SOM (Simpson et al., 2007; Liang et al., 2011; Hobara et al., 2014), which has been elucidated in the ocean (Kawasaki and Benner, 2006; Kaiser and Benner, 2008; Jiao et al., 2010). The composition and transformations of aquatic $\mathrm{C}$ are increasingly being used to better understand the terrestrial systems whence some fraction of aquatic $\mathrm{C}$ is derived. Indeed, the Battin et al. "boundless $\mathrm{C}$ cycle" concept emphasizes the importance of aquatic $\mathrm{C}$ flows as essential to quantify if we wish to understand both terrestrial and aquatic $\mathrm{C}$ transformations (Battin et al., 2009), and yet more recent work highlights how OM composition in aquatic systems can help us understand both aquatic $\mathrm{C}$ fluxes and the terrestrial systems upstream (MarínSpiotta et al., 2014).

The stoichiometry of resources and of microbial resource demand are both relevant to OM decay and retention because microbial stoichiometry governs the resources that can be used effectively and thus the stocks of OM (including microbial necromass) that are retained (Elser et al., 2000). Adding $\mathrm{C}$ to lake water, for example, can induce greater bacterial biomass and greater bacterial mass-specific uptake of phosphorus (P; Stets and Cotner, 2008). However, this effect is attenuated when grazing by organisms in higher tropic levels limits the pool size of bacterial biomass (Stets and Cotner, 2008). Thus, it seems important to investigate the extent to which soil food webs can provide a top-down limitation on 
the turnover of SOM after $\mathrm{C}$ additions. Knowledge of bacterial responses to $\mathrm{C}$ additions from the aquatic literature is also relevant to investigations of the distinctions between bulk soil SOM transformations and those in the rhizosphere, where $\mathrm{C}$ availability tends to be higher (Cheng et al., 2014), and can help us understand both lateral and vertical patterns of nutrient demand in soils.

Indeed, experiments in freshwater lakes also reveal that changes in bacterial stoichiometry with changing resource stoichiometry are dwarfed by the responses of biomass stoichiometry to changing growth rates (Makino et al., 2003). Stoichiometric plasticity of microorganisms, though acknowledged as a potentially important way in which microbes may respond to environmental change (Billings and Ballantyne, 2013), is rarely incorporated into conceptual or quantitative models of SOM transformations, in stark contrast to the aquatic literature (e.g., Klausmeier et al., 2007). The degree to which organisms exhibit stoichiometric flexibility appears to vary widely (Geider and Laroche, 2002), but in organisms exhibiting such plasticity, $\mathrm{C}: \mathrm{P}$ can be many times more variable than $C: N$ (Hessen et al., 2013). It is unknown how such variation may influence OM decay, whether in aquatic or soil environments, but because one or multiple resources ultimately limit growth and rates of decomposition, understanding the causes and consequences of microbial stoichiometry in soils is important for modeling SOM degradation and associated respiratory $\mathrm{C}$ loss.

Aquatic scientists also have observed that increasing temperatures tend to result in increasing $\mathrm{C}: \mathrm{P}$ and $\mathrm{N}: \mathrm{P}$ of bacterial biomass (Cotner et al., 2006), and that some of these changes are driven by changes in community composition (Hall et al., 2008). Bacterial growth efficiency (production/(production + respiration); delGiorgio and Cole, 1998) appears to decline with warming in aquatic systems (Hall and Cotner, 2007) and to be lower in tropical compared to temperate lakes (Amado et al., 2013), though this warming response is not ubiquitous (delGiorgio and Cole, 1998). Lower respiratory C losses at a particular temperature from bacteria sampled from warmer environments compared to those sampled from colder environments are congruent with microbial acclimation to temperature regimes (Hall and Cotner, 2007). Currently, the efficiency with which soil microbes generate biomass relative to $\mathrm{CO}_{2}$ (often referred to as C use efficiency, or CUE) is a key focus of SOM investigations, but aquatic literature suggests that variables like biomass pool size (driven by both bottom-up and topdown pressures, Amado et al., 2013) and biomass stoichiometry $(\mathrm{C}: \mathrm{N}: \mathrm{P})$ should be included in soil-focused studies of microbial CUE.

\subsection{Chemostats as well-mixed, reductionist environments in which to explore drivers of microbial elemental composition}

Chemostat experiments enable almost complete control over microbial growth dynamics, and thus are useful for exploring fundamental microbial responses to environmental variation. Scientists have used chemostats for decades to understand the determinants of microbial growth (Monod, 1950; Droop, 1974; Rhee and Gotham, 1981) because microbial growth rate can be controlled via dilution rate (Table 1; Monod, 1950, see Ferenci, 2008, for discussion). Unfortunately we cannot know microbial growth rates in non-steady state conditions. However, the benefits of exploring microbial behaviors in continuous culture mode are great, given how difficult it is to know microbial growth rates in soils and their importance for understanding microbial responses to environmental cues.

In recent years, chemostat studies have enjoyed a resurgence in popularity (e.g., Miller et al., 2013; Simonds et al., 2010), driven in part by investigations of bacterial responses to environmental change and associated patterns of gene expression (Ferenci, 2008). For example, components of recent models of SOM transformations such as the stoichiometric constraints on substrates, enzymes, and microbial biomass (Moorhead et al., 2012; Manzoni et al., 2012a; Allison, 2012; Ballantyne IV and Billings, 2015) are frequently investigated in chemostat studies. Though some models invoke plasticity of microbial stoichiometry as a potential response to environmental change, the extent to which biomass plasticity vs. homeostasis is realized, and under what conditions, remains unclear. While total soil microbial biomass $\mathrm{C}: \mathrm{N}: \mathrm{P}$ appears well-constrained to an average of 60:7:1 across multiple ecosystems and a wide range of nutrient availabilities (Cleveland and Liptzin, 2007), studies manipulating soil nutrients demonstrate that meaningful shifts in microbial stoichiometry are sometimes realized (Tiemann and Billings, 2011b). Where plastic biomass stoichiometry is observed, two key reasons make it difficult to understand the mechanisms underlying the phenomenon: (1) it is difficult to know if such shifts result from stoichiometric change in extant populations or from changing relative abundances of distinct populations, and (2) stoichiometric analyses of soil microbial biomass typically reflect total biomass, not just the active biomass (Table 1). Chemostats allow us to disentangle these competing mechanisms.

In a chemostat, changes in biomass stoichiometry provide evidence that microbial stoichiometric plasticity can be a consequence of environmental change, a conclusion difficult to formulate using soil in which we do not know the identity or the abundance of the active microbial players. Stoichiometric plasticity of microbes can vary to a much greater extent than what is typically observed in SOM literature. For example, Pseudomonas fluorescens biomass C:N:P showed variation from $52: 8: 1$ to $163: 25: 1$, depending on 
Table 1. Parameters frequently of interest for empirical and theoretical investigations of SOM transformations (left column), typical challenges encountered when interpreting data derived from soil studies (middle column), and the benefits of employing chemostats (rows 1 through 3, last column) and purified substrate-enzyme reactions (row 4, last column). Controlled environments where microbial populations and environmental conditions can be strictly monitored provide unique insights that can be used to develop hypotheses for soil-based studies or parameterize models of SOM transformations. See Sects. 2 and 3 for detailed explanation of all table cells.

\begin{tabular}{|c|c|c|}
\hline $\begin{array}{l}\text { Soil parameter } \\
\text { of interest }\end{array}$ & Challenges for soil based studies & $\begin{array}{l}\text { Benefits of chemostat-based studies (rows 1-3) } \\
\text { Benefits of purified, abiotic studies (row 4) }\end{array}$ \\
\hline $\begin{array}{l}\text { Carbon use } \\
\text { efficiency (CUE) }\end{array}$ & $\begin{array}{l}\text { - Recycling of isotopic label through microbial biomass } \\
\text { is likely across diverse timescales. } \\
\text { - Growth rate is unknown. }\end{array}$ & $\begin{array}{l}\text { - Growth rate is known. } \\
\text { - Growth rate can be manipulated. } \\
\text { - Isotopic fractionation can be quantified. } \\
\text { - Fraction of dead cells is small. }\end{array}$ \\
\hline $\begin{array}{l}\text { Microbial stoichiomet- } \\
\text { ric plasticity }\end{array}$ & $\begin{array}{l}\text { - Stoichiometric change may occur in extant popula- } \\
\text { tions, or from changing relative abundances of distinct } \\
\text { populations. } \\
\text { - Stoichiometric analyses of soil microbial biomass typ- } \\
\text { ically reflect total biomass, not just active biomass. }\end{array}$ & $\begin{array}{l}\text { - The identity, pool size, and growth rates of the active } \\
\text { microbes are all known. }\end{array}$ \\
\hline $\begin{array}{l}\text { Environmental controls } \\
\text { on gene expression }\end{array}$ & $\begin{array}{l}\text { - Metatranscriptomes or functional gene transcription } \\
\text { are dependent on growth rates, nutrient availability, and } \\
\text { environmental controls on transcription rates that are } \\
\text { unknown. }\end{array}$ & $\begin{array}{l}\text { - Growth rates are known, nutrient availability is con- } \\
\text { stant, and gene expression can be monitored as individ- } \\
\text { ual environmental signals are manipulated. }\end{array}$ \\
\hline $\begin{array}{l}E_{\mathrm{a}} \text { and associated } \\
\text { temperature sensitivity } \\
\text { of SOM decay }\end{array}$ & $\begin{array}{l}\text { - Differences among soils in apparent } E_{\mathrm{a}} \text { may result } \\
\text { from different microbial physiology, microbial commu- } \\
\text { nity structure, or substrate availability, and not from in- } \\
\text { herent differences in substrate } E_{\mathrm{a}} \text { of decay. }\end{array}$ & $\begin{array}{l}\text { - Intrinsic kinetics of decay can be quantified in con- } \\
\text { trolled conditions and under varying environmental pa- } \\
\text { rameters such as } \mathrm{pH} \text { and temperature. } \\
\text { - The } \mathrm{C}: \mathrm{N} \text { flow ratio can be computed as environmen- } \\
\text { tal conditions change, reflecting how } \mathrm{C} \text { and } \mathrm{N} \text { availabil- } \\
\text { ity can change even in the absence of microbial adapta- } \\
\text { tion. }\end{array}$ \\
\hline
\end{tabular}

whether $\mathrm{P}$ was abundant or scarce relative to $\mathrm{N}$ (Chrzanowski and Kyle, 1996). Chemostats also have revealed that some stoichiometric ratios (e.g., C:N) of actively metabolizing microorganisms can remain similar as nutrient availability changes, while others (e.g., N:P) vary only when a substrate stoichiometric threshold is surpassed (Chrzanowski and Kyle, 1996). It remains unclear if stoichiometric plasticity represents opportunistic uptake in response to changing nutrient availability, or if it is a reflection of a microbial population's inability to regulate uptake and/or excretion. Regardless of the mechanism, changing microbial stoichiometry can influence both resource demand and, given the generation of microbial necromass, SOM composition.

Chemostats are also a key means of advancing our knowledge about microbial stoichiometry in different temperature regimes and at different growth rates. Chemostats inform us, with great clarity, that growth rate and in some circumstances temperature are key drivers of microbial stoichiometry. Growth rate appears to be a dominant driver of stoichiometric patterns in chemostat-raised organisms (Rhee and Gotham, 1981; Klausmeier et al., 2007; Chrzanowski and Grover, 2008), consistent with observations from lakes (Makino et al., 2003). Microbes growing at relatively fast rates tend to exhibit greater cellular $\mathrm{P}$ concentrations across a range of $\mathrm{P}$ availabilities, consistent with observations from natural waters (Elser et al., 2003) and the growth rate hy- pothesis (GRH), which states that $\mathrm{C}: \mathrm{P}$ and $\mathrm{N}: \mathrm{P}$ ratios reflect changing organismal allocation to ribosomal RNA, a P-rich molecule, as growth rate varies (Elser et al., 2000). Bacterial stoichiometry $(\mathrm{C}: \mathrm{P}, \mathrm{N}: \mathrm{P})$ also appears to vary with temperature in nutrient-limited $(\mathrm{N}, \mathrm{P})$ environments, perhaps due to greater investment in P-rich RNA at cooler temperatures (Cotner et al., 2006). Interestingly, the effects of temperature and growth rate on cellular P content may cancel each other when cell growth is not proceeding at the maximum rate as would be the case in batch culture (Cotner et al., 2006), highlighting the complexity of the interactions driving microbial stoichiometry.

\subsection{Chemostats as well-mixed, reductionist environments in which to explore $\mathrm{C}$ fluxes}

Chemostats also allow us to study how the fate of C substrates changes with changing environmental conditions in a manner impossible in soils. A flurry of recent studies investigating microbial $\mathrm{C}$ flows with changing soil conditions highlights how microbial $\mathrm{C}$ fate dictates the magnitude of soil feedbacks to climate (Manzoni et al., 2012a; Wieder et al., 2013; Sinsabaugh et al., 2013), but without knowing the rate at which soil microorganisms are growing and what limits their growth, we cannot know the fraction of $\mathrm{C}$ uptake allocated to growth vs. respired $\mathrm{CO}_{2}$ (typically expressed as 
the CUE), and thus the gross $\mathrm{CO}_{2}$ flux from soil. It follows that it is exceedingly difficult to assess how the propensity to generate biomass vs. $\mathrm{CO}_{2}$ might change with environmental conditions (Table 1). Adding an isotopically labeled substrate can help us understand microbial uptake of a particular resource or suite of substrates (e.g., Ziegler et al., 2005; Li et al., 2012; Frey et al., 2013), but we must interpret resultant data with the knowledge that we have perturbed the natural system, and that recycling of the isotopic label through the microbial biomass is likely to confound inferences from such studies as the temporal extent of sampling increases.

Recently, Lehmeier et al. (2015) exploited the chemostat environment to investigate the consequences of changing temperature regime on $\mathrm{C}$ flux from $\mathrm{OM}$ substrate into microbial biomass, and into respired $\mathrm{CO}_{2}$. At a constant rate of growth, microorganisms experienced an increase in specific respiration rate and a corresponding decline in CUE with increasing temperature. This work substantiates inferences from soil-based studies that CUE declines with temperature (e.g., Frey et al., 2013). The CUE finding is critical for efforts to incorporate soil processes into Earth system models used to predict future atmospheric $\mathrm{CO}_{2}$ concentrations (Wieder et al., 2013).

Second, this study also highlighted strong isotopic fractionations among substrate, biomass, and respired $\mathrm{CO}_{2}$ pools that vary with temperature (Lehmeier et al., 2015). Apparent respiratory fractionation during fungal (Henn and Chapela, 2000) and bacterial (Blair, 1985) respiratory losses of $\mathrm{CO}_{2}$ has been observed, but is difficult to interpret when microbial growth rate is not known and the system is not at steady state. Isotopic fractionation during $\mathrm{CO}_{2}$-generating respiratory fluxes is rarely considered in studies that use $\delta^{13} \mathrm{C}-\mathrm{CO}_{2}$ to infer mesocosm or ecosystem function, though the potential importance of this phenomenon in plant respiration across diverse scales has been noted (Pataki, 2005). Because of difficulties knowing which active microbial population produced measured $\mathrm{CO}_{2}$, or the substrate from which it was derived, it is difficult to quantify isotopic fractionation effects among organic and inorganic $\mathrm{C}$ pools in soil-based studies. Lehmeier et al. (2015) demonstrate the importance of chemostat studies for avoiding these soil-based challenges and provide proof of concept for temperature dependence of a respiratory fractionation factor. In contrast to studies in which soil temperature is manipulated, chemostats demonstrate that isotopic variation in respired $\mathrm{CO}_{2}$ can result even while holding constant substrate identity and availability, active microorganism identity, and microbial growth rate.

Importantly, other chemostat studies have demonstrated that microbial growth rate itself, in isolation from other conditions such as temperature or nutrient availability, appears to influence specific respiration rates (Larsson et al., 1993; Payot et al., 1998; Kayser et al., 2005). This is consistent with the GRH (Elser et al., 2000). However, soil biogeochemists and microbial ecologists typically presume that a combination of resource availability and community composition de- termines the size and growth efficiency of a microbial community, which in turn influences the respiratory $\mathrm{C}$ efflux, and that changing environmental conditions (e.g., temperature) can induce changes in specific respiration rate. Chemostat studies, however, demonstrate that growth rate governs not only specific respiration (Kayser et al., 2005) but also the relative dominance of respiratory pathways that produce $\mathrm{CO}_{2}$ (Nanchen et al., 2006). If growth rate is a driver of specific respiration in soil microbial communities, these data suggest an important and underappreciated mechanism driving microbially mediated soil C fluxes.

\subsection{Chemostats as well-mixed, reductionist environments in which to explore microbial gene expression}

Chemostats present the ideal conditions for linking gene expression to biogeochemically relevant fluxes, which are transferrable to soils. Patterns of microbial gene expression are often considered the gold standard for understanding microbial community function in a multitude of environments (Ottesen et al., 2014; Ofek-Lalzar et al., 2014), and microbial gene expression in soils is obviously of great relevance to questions of SOM decay and soil microbial ecology more generally (Baldrian and López-Mondéjar, 2014). However, as outlined by Schimel and Schaeffer (2012), using modern molecular tools to better understand SOM decay is challenging given the lack of specificity of decay-related genes; unlike processes like methanogenesis and methanotrophy or denitrification, SOM decay is governed by a relatively large number of genes residing in a greater diversity of organisms. Despite the seemingly daunting level of microbial genetic diversity, soil metagenomes can be mined for their annotated and functionally assigned genes, and then used to assess how potential metabolic pathways can shift with changes in the environment such as soil warming (Luo et al., 2014). New tools such as Functional Ontology Assignments for Metagenomes (FOAM, Prestat et al., 2014) are making it even easier to use metagenomic data to group microbial communities based on broadly categorized metabolic processes. This is an important step forward as it has been recently demonstrated that even inclusion of coarse, physiologically defined functional groupings, e.g., oligotrophs versus copiotrophs, can improve models of litter and SOM decay (Wieder et al., 2014).

Understanding and predicting microbial gene expression is challenging, in part because patterns of gene expression in soils are driven by both bacterial growth rates (Ferenci, 1999) and the identity of any limiting nutrient (Hua et al., 2004) (Table 1). Thus, changes we observe in soil transcriptomes with environmental conditions may not be the direct result of, for example, a temperature change, but instead may result from altered growth rates and/or changes in relative nutrient availability as induced by the change in temperature. These gaps in our knowledge can be filled through the use 
of chemostats. In a controlled chemostat environment where nutrient availability is constant and growth rates can be monitored, researchers can measure gene expression in response to isolated environmental stressors such as osmotic potential or temperature changes. For example, in a controlled chemostat-like system, Gülez et al. (2012) examined gene expression in relation to stress induced by manipulating matric potential. Hebly et al. (2014) used a chemostat approach to quantify changes in gene transcription and physiology of Saccharomyces cerevisiae during cyclic 12 to $30^{\circ} \mathrm{C}$ shifts in daily temperature, and demonstrate the importance of microbial acclimation to temperature at these short timescales. These studies are of direct relevance to SOM-related investigations of the influence of soil water stress and temperature on SOM transformations. As we increase our understanding of the environmental controls on gene expression and transcription networks, we can begin to understand how the snapshot of whole community gene transcription represented by a soil metatranscriptome is linked to changes in the physiology of the community, and observed changes in soil processes such as SOM decay. These research avenues are critical for formulating and parameterizing SOM decay models, discussed in Sect. 3.

Both natural and artificial aquatic systems are increasingly viewed as relevant to soil studies (e.g., Marín-Spiotta et al., 2014; Lehmeier et al., 2015), and we applaud such efforts. However, though sometimes used in conjunction with natural aquatic environments (Sterner et al., 2008), chemostats are only just beginning to be explored in the context of soilspecific questions, and can provide knowledge about $\mathrm{OM}$ decay not feasible to obtain using natural soil profiles. In the next section, we explore another underexploited concept relevant to SOM transformations - that of intrinsic vs. apparent exo-enzyme kinetics. Though different soils may exhibit different apparent $E_{\mathrm{a}}$, it is difficult if not impossible to know the extent to which intrinsic properties of a soil's substrates vs. other, soil-specific, features govern apparent $E_{\mathrm{a}}$.

\section{Intrinsic decay rates as baseline values for comparison with observed patterns of SOM decay}

Multiple studies explore apparent activation energies (apparent $E_{\mathrm{a}}$; in $\mathrm{kJ} \mathrm{mol}^{-1}$ ) required for SOM decay to proceed, often in the context of investigating the temperature sensitivity of SOM decay. The $E_{\mathrm{a}}$ is one way to quantify the ease with which decay of compounds can proceed. A substrate with intrinsically higher $E_{\mathrm{a}}$ is more difficult to decay than one with lower $E_{\mathrm{a}}$ at a given temperature (Sierra, 2012) and, accordingly, the $\mathrm{C}$ quality-temperature hypothesis suggests that OM more resistant to decay should exhibit higher relative temperature sensitivity (Bosatta and Ägren, 1999; Davidson and Janssens, 2006). Apparent $E_{\mathrm{a}}$ thus represents one means of quantifying more qualitative terms like "recalcitrance" and "quality" that are difficult to interpret (Kleber,
2010; Kleber et al., 2010; Conant et al., 2011). Apparent $E_{\mathrm{a}}$ is clearly an important feature to consider when investigating soil feedbacks to climate because in a warmer environment SOM exhibiting long residency times may exhibit greater relative increases in decay rates than SOM that decays more rapidly. However, it is difficult to interpret why one soil's apparent $E_{\mathrm{a}}$ may be different from another's, for we cannot know if the substrates undergoing decay possessed different intrinsic $E_{\mathrm{a}}$ of decay, or if soil-specific factors such as texture or the identity of the active microbial community drove apparent $E_{\mathrm{a}}$ differences. Selecting ubiquitous substrates and some of the key biogeochemical reactions that induce their decay, and characterizing the kinetics of these reactions when isolated from other substrates and microbes themselves, represents an incremental movement towards addressing these questions. This approach will provide estimates of reaction rates and estimates of $E_{\mathrm{a}}$ that are as close to intrinsic values as is feasible if they are conducted when neither enzyme nor substrate is limiting.

It is important to consider the drivers of differences among potential and observed reaction rates, and apparent and intrinsic $E_{\mathrm{a}}$, for a specific decay reaction when interpreting decay reaction rates and apparent $E_{\mathrm{a}}$ values derived from the soil environment. Recalling that the slope of an Arrhenius plot is considered the $E_{\mathrm{a}}$ of a reaction, we first must note that the line defining intrinsic $E_{\mathrm{a}}$ should, in theory, always be above (have a higher $y$ intercept than) any line defining apparent $E_{\mathrm{a}}$. This follows from the assumption that a decay reaction rate quantified in purified, abiotic solutions when neither enzyme nor substrate is limiting represents the upper limit for that reaction rate at that temperature. This is a difficult hypothesis to test because the units in which purified substrate-enzyme reaction rates are expressed must necessarily be different from the typical units employed in studies of exo-enzyme reactions in soils and sediments (e.g., Sinsabaugh et al., 2012), but its logic is difficult to challenge.

In spite of the difficulties associated with directly comparing the temperature sensitivities of pure substrate-enzyme kinetics and actual SOM decomposition, it is valuable to consider the multiple ways in which apparent $E_{\mathrm{a}}$ of decay reactions in soils exposed to different temperatures may vary relative to intrinsic $E_{\mathrm{a}}$ for those same reactions. Because the slope estimates $\left(E_{\mathrm{a}}\right.$ in $\left.\mathrm{kJ} \mathrm{mol}^{-1}\right)$ are independent of the reaction rate units, they can be compared and yield meaningful interpretations across samples. In some soils, we may observe an apparent $E_{\mathrm{a}}$ greater than intrinsic $E_{\mathrm{a}}$ for a particular substrate-enzyme reaction (a steeper slope in an Arrhenius plot). However, it is feasible that some environmental samples may exhibit lower apparent $E_{\mathrm{a}}$ (a shallower slope), or equivalent $E_{\mathrm{a}}$ (parallel slope; note that $y$ intercepts for Arrhenius plots depicting apparent $E_{\mathrm{a}}$ will always be equal to or lower than those depicting intrinsic $E_{\mathrm{a}}$ as discussed above). A lower apparent $E_{\mathrm{a}}$ may occur if, for example, cooler temperatures promoted a competitive advantage for microbial populations that preferentially produce the exo- 
enzyme that catalyzes the reaction in question, boosting observed reaction rates to a greater extent than the direct influence of temperature on the purified reaction rate would predict. It remains unknown how changing temperature regimes may result in changing competitive advantages for different microbial groups, however. Alternatively, soil moisture may decrease with increasing temperature, constraining diffusion (Wang et al., 2014), or warming could affect plant inputs to soil in multiple ways (Flury and Gessner, 2014). Either of these phenomena could alter microbial demand for substrates and thus modify exo-enzyme production, pushing observed reaction rates away from intrinsic reaction rates differentially across a temperature range.

Lehmeier et al. (2013) determined reaction rates of $\beta$-Dcellobioside as catalyzed by $\beta$-glucosidase (BGase) and $\mathrm{N}$ acetyl- $\beta$-D-glucosamine (NAG) as catalyzed by $\beta$-N-acetyl glucosaminidase (NAGase) in purified (and therefore nonconfounding, ideal conditions) at temperatures between 5 and $25^{\circ} \mathrm{C}$ and a $\mathrm{pH}$ of 6.5 . These reactions are proxies for the cleaving of monomers from cellulose and chitin, respectively. Because they were conducted when neither enzyme nor substrate was limiting, the study provided $E_{\mathrm{a}}$ values of these compounds $\left(31 \mathrm{~kJ} \mathrm{~mol}^{-1}\right.$ for BG/BGase, $41 \mathrm{~kJ} \mathrm{~mol}^{-1}$ for NAG/NAGase), which are as close to intrinsic values as is feasible. Expanding on this study, Min et al. (2014) confirmed the values and explored how the $E_{\mathrm{a}}$ of these reactions change when the $\mathrm{pH}$ was varied in a reasonable range for soil $\mathrm{pH}$ around the world. They reported distinct $\mathrm{pH}$ optima for both BG/BGase (5.5-8.5) and NAG/NAGase (5.5-6.5), and a significant effect of $\mathrm{pH}$ on the temperature sensitivity of BGase but not NAGase (Fig. 1). Baseline, intrinsic properties of these reactions in multiple $\mathrm{pH}$ regimes helps us to develop biogeographically based predictions of the temperature response of cellulose and chitin decay.

Such baseline values for intrinsic $E_{\mathrm{a}}$ only represent conditions in which neither enzyme nor substrate is limiting, a scenario that is only sometimes relevant to soils. However, baseline values are nonetheless essential for comparisons with estimates of apparent $E_{\mathrm{a}}$ of cellulose and chitin decay derived from soil samples. For example, estimates for apparent $E_{\mathrm{a}}$ of the $\mathrm{BGase} / \mathrm{BG}$ reaction derived from diverse soils exhibit varying values compared to intrinsic $E_{\mathrm{a}}$ values assessed in purified conditions (Fig. 1a). Though some papers present apparent $E_{\mathrm{a}}$ values from soils for the NAGase/NAG reaction (e.g., German et al., 2012), it is difficult to find those that present units comparable among studies. The few that do (Fig. 1b) suggest meaningful variation in values (Fig. 1b). If apparent $E_{\mathrm{a}}$ values are greater than intrinsic values, this suggests that soil-related factors confounding the intrinsic temperature response of the NAGase/NAG reaction become relatively more influential at lower temperatures. In contrast, soil-related factors confounding intrinsic $E_{\mathrm{a}}$ for the BGase/BG reaction appear to both increase and decrease apparent $E_{\mathrm{a}}$ relative to intrinsic values. Assessing $E_{\mathrm{a}}$ values at the actual soil $\mathrm{pH}$, not at an arbitrary buffer $\mathrm{pH}$, may of- fer important insights too. For instance, Barta et al. (2014) demonstrated the $\mathrm{BGase} / \mathrm{BG}$ reaction can proceed in soils at $\mathrm{pH}$ 3.5. This is in apparent contrast to Min et al. (2014), where BGase/BG activity at $\mathrm{pH}$ lower than 4.5 could not be detected in purified conditions. The reasons for this discrepancy remain unclear, but one possible explanation is the microbial generation of distinct isozymes capable of inducing catalysis in low $\mathrm{pH}$ environments. This and related insights are impossible to generate without developing baseline intrinsic $E_{\mathrm{a}}$ values. Similar work on a diversity of substrateenzyme pairings will provide an important knowledge base for future SOM decay research.

Values of intrinsic $E_{\mathrm{a}}$ of decay reported thus far suggest that the influence of temperature on exo-enzymes, even in isolation from all the other changes that temperature can impart on soils, is important for the relative availability of resources for microbial assimilation. Specifically, studies indicate how temperature alone can alter the relative availability of $\mathrm{C}$ and $\mathrm{N}$ liberated from substrates as they decay - the $\mathrm{C}: \mathrm{N}$ flow ratio - if those substrates have distinct $\mathrm{C}: \mathrm{N}$ ratios and $E_{\text {a }}$ of decay (Billings and Ballantyne, 2013). Exo-enzyme age also appears to interact with temperature to influence the relative availability of $\mathrm{C}$ and $\mathrm{N}$ released during decay reactions; the catalytic rate of exo-enzymes and the temperature at which the enzyme ages prior to catalyzing decay reactions can influence the decay rate of BG and NAG differently (S. Billings, unpublished data). The $\mathrm{C}: \mathrm{N}$ flow ratio is important because it represents the return on microbial investments in exo-enzymes, and how that return on investment may change with temperature in ways that have nothing to do with microbial responses to temperature per se. Because changing relative availability of microbial resources may influence microbial stoichiometry (see Sects. 2.1 and 2.2), and, in turn, decay of additional substrates, exploring additional drivers of changing $\mathrm{C}: \mathrm{N}$ flow rates appears to be an important, complementary avenue of research.

\section{Using experimental advances to enhance recent theoretical efforts to model SOM decay}

Investigators have modeled SOM decay for decades. Though an exhaustive review of these advances is beyond the scope of this paper, we highlight recent advances and elucidate how these advances could benefit from some of the discoveries detailed above. Coarsely, models of SOM decay can be grouped into two categories: those that are spatially explicit, and those that implicitly treat the factors influencing SOM decay as spatially homogeneous. The first category comprises models such as reactive transport models, often invoked by engineers or hydrologists (Masse et al., 2007; Scheibe et al., 2009), while the second category is more familiar to ecologists (Schimel and Weintraub, 2002; Allison, 2005; Allison et al., 2010; Davidson et al., 2012; Manzoni et al., 2012a; Moorhead et al., 2012; Moyano et al., 2013; Bal- 

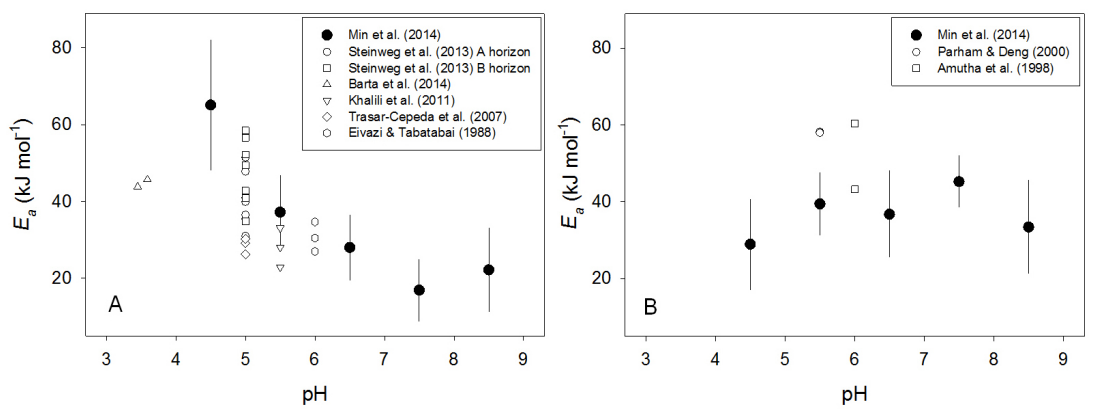

Figure 1. Estimates of intrinsic (closed symbols) and apparent (open symbols) $E_{\mathrm{a}}$ for the BGase/BG reaction (a) and the NAGase/NAG reaction (b). The literature values for apparent $E_{\mathrm{a}}$ are shown at the $\mathrm{pH}$ at which the reaction was actually observed, and does not necessarily correspond to the $\mathrm{pH}$ of the soils from which the samples were taken. See Sect. 3 for interpretation.

lantyne IV and Billings, 2015). Recent work begins to merge both abiotic properties of soils and plastic vs. homeostatic microbes (Tang and Riley, 2015), and some efforts have incorporated space into ecologically focused models by considering diffusional constraints on exo-enzymes within the soil matrix (Allison, 2005; Allison et al., 2010; Manzoni et al., 2014). However, realistic physics of diffusion are rarely incorporated into models that explicitly consider microbes, and thus it is difficult to know if the temporal and spatial scales invoked for modeled diffusion are appropriate. Comparing substrate usage in chemostats or natural aquatic environments to that in soils can be valuable for discerning the influence of diffusion constraints on OM transformations, given minimal diffusion limitation in liquid environments relative to that in soils. However, empirical measurements of enzyme flow in soil (e.g., Vetter et al., 1998) highlight how difficult it is to generate realistic enzyme movements in a diffusion-constraining matrix, and the challenges of integrating spatially distinct processes into ecologically focused process models. This category distinction is important because processes relevant to SOM decay occur at the fine scales typically envisioned by ecological modelers (Schimel and Schaeffer, 2012), but key goals of the community are to predict SOM decay and associated $\mathrm{CO}_{2}$ release at far coarser scales (e.g., Wieder et al., 2013). Thus at its core, projecting decomposition of SOM processes relevant at the Earth system scale is an exercise in accurate physiological and physical modeling combined with scaling approaches.

Multiple modeling efforts have attempted to move us toward the goal of projecting large-scale SOM transformations from physiologically based models, and recent years have seen a proliferation of models describing SOM decay (Manzoni and Porporato, 2009). Only rarely have investigators tried to estimate both model parameter values and the variance in those estimates from empirically derived data (Davidson et al., 2012), and quantitative results are difficult to apply across diverse soil types, ecosystems, and climate regimes. As a result, most of the insights provided by SOM decay models are qualitative. These models attempt to model SOM transformations by incorporating factors known or thought to govern SOM decay rates and associated $\mathrm{CO}_{2}$ efflux, such as microbial growth rates, CUE, allocation of $\mathrm{C}$ to enzyme production, and $\mathrm{C}$ uptake rates (Allison et al., 2010; Allison, 2012; Manzoni et al., 2014). However, many models assume fixed fractions of microbial $\mathrm{C}$ allocated to processes such as enzyme production and maintenance metabolism, contrasting with evidence from physiological experiments which indicate that allocation patterns shift with the interplay between microbial resource demand and availability (Larsson et al., 1993; Payot et al., 1998; Dauner et al., 2001; Dijkstra et al., 2011).

The omission of microbial physiological plasticity in these and related models is unfortunate because it is the fundamental microbial physiology that shapes $\mathrm{C}$ flow through microbial biomass and associated CUE (Billings and Ballantyne, 2013). An important advance relates aggregate $C$ fluxes through soil microbes to microbial CUE (Manzoni et al., 2012a), critical both because this term governs the propensity of soil organic carbon (SOC) to remain in the soil profile vs. leaving as $\mathrm{CO}_{2}$, and because CUE is a "tunable" parameter in multiple other models (e.g., Wieder et al., 2013). Importantly, though, CUE is not a parameter that microbes govern as an end goal; rather, CUE is a byproduct of the changing relative importance of anabolism and catabolism as metabolic resource demand and resource availability vary in response to environmental conditions. An important step forward will be to develop models that do not modify only CUE, but that reflect multiple changes in environmental conditions influencing microbial stoichiometry and metabolism, with CUE changing as a result. Chemostat data again become important for these modeling efforts because they provide baseline values for biomass production and specific respiration rates under varying environmental conditions which, in turn, dictate $\mathrm{CO}_{2}$ efflux from soils.

Developing a theoretical scaffolding on which we can build physiologically mechanistic models that ultimately can be made spatially explicit, and thus useful for modeling at the scale of the Earth system, will require two key advances. 
First, more physiological realism needs to be incorporated into our modeling frameworks. Enhancing the physiological realism of existing ecological models can take multiple forms. Regulatory-metabolic network models that reflect microbial decision making and metabolic constraints can be developed. Metabolic flux analysis can be an effective means of modeling in situ metabolic transformations in soils (e.g., Scheibe et al., 2009), but progress in this realm remains slow (but see Dijkstra et al., 2011). Interdisciplinary studies such as Tang et al. (2009), who highlighted how ${ }^{13} \mathrm{C}$ and multiple "-omics" fields can be effectively integrated, represent large strides towards the development of this field. Importantly, chemostats represent ideal experiments from which to build such models. Gene expression and proteomics measured in chemostats under constant conditions provide the best chance for matching expression and network state to putative $\mathrm{C}$ transformations. Additionally, parameter values for microbial substrate uptake, mass of $\mathrm{C}$ per unit dry mass of microbial biomass, dry weight per cell, enzyme deactivation rate, and the microbial biomass fraction of $\mathrm{N}$ and P (e.g., Allison, 2012; Manzoni et al., 2014) are available for changing environmental conditions from chemostat studies (e.g., Chrzanowski and Kyle, 1996; Chrzanowski and Grover, 2008; Lehmeier et al., 2015). Though the absolute values from reductionist laboratory experiments may not be directly applied to soils, they are a great starting point for accurately parameterizing models. Values of $E_{\mathrm{a}}$ for SOM decay are typically treated as one aggregated value as a simplifying assumption (e.g., Allison et al., 2010), though we know this to be false. Estimates of intrinsic $E_{\mathrm{a}}$ values derived from purified, biogeochemically relevant enzymes (Lehmeier et al., 2013; Min et al., 2014) are analogous starting points for parameterizing decay kinetics, which result from regulatory-metabolic network driven allocation and feedback upon physiological state.

Second, we must accurately average SOM transformations and heterotrophic respiration over heterogeneity in the soil matrix to extract responses at reasonable scales for Earth system modeling. This exercise of "coarse graining" will enable modelers to identify characteristic scales associated with SOM transformations, and in the process improve our understanding of how edaphic and biological features interact in generalizable ways. Once characteristic scales have been identified, spatially explicit model dynamics can then be compared to those of non-spatial ecological models. This will enable ecological model dynamics to be applied at appropriate scales with appropriate parameters. There are two approaches widely employed in other fields that could be used for coarse graining SOM dynamics. One is to start with individual dynamics, as in Masse et al. (2007), and then derive the dynamics of the aggregate, in this case the entire soil profile, from the individual level dynamics. Durrett and Levin (1994) refer to this as deriving a hydrodynamic limit because of the analogous derivation of Navier-Stokes equations from the mass transfer for individual parcels of liquid.
From such limits, characteristic length scales can often be inferred. Another approach is to start again with individuallevel dynamics, but with stochasticity, and then derive mean dynamics for a profile or site in terms of higher-order moments. This gives rise to the problem of moment closure, but moment closure methods have been effectively applied to model the mean dynamics of spatially explicit ecological dynamics (Bolker and Pacala, 1997). Successfully averaging over the heterogeneity we know exists in soils will allow us to capture the important governors of SOM transformations at scales relevant for Earth systems models. By initially considering the full extent of heterogeneity and then employing robust analytical methods to translate the consequences of that heterogeneity for dynamics at larger scales, i.e., whole soil profiles over reasonable spatial extents, we will obtain more realistic projections of SOM dynamics as well as more meaningful measures of confidence in those projections.

\section{Applying these concepts to the puzzles presented by changing SOM characteristics with depth}

We can apply some of the empirical and theoretical concepts described above to help address the question we posed in the introduction: why does some SOM leave the soil profile relatively quickly, while other compounds, especially those at depth, appear to be retained on timescales ranging from the decadal to the millennial? In recent years, the community of scholars focused on SOM transformations has become increasingly appreciative of the importance of relatively deep SOM. Indeed, investigators are establishing Critical Zone Observatories around the globe to investigate whole-ecosystem function down to bedrock (Jordan et al., 2001), and are developing an increasing appreciation of the importance of deep metabolic processes for ecosystem functioning (Richter and Billings, 2015). It is difficult to define what is meant by "deep SOM". Absolute depths are arbitrary, and using the plant rooting zone as an indicator of "shallow" horizons is challenging when we consider highly weathered profiles in which active plant roots can function tens of meters below the surface (Stone and Kalisz, 1991), surrounded by SOM we might otherwise consider to be "deep". However, general trends in SOM stability with depth are clear: with depth, SOM stability appears to increase, with mean residence times of millennia not uncommon (Trumbore, 2009; Schmidt et al., 2011, Fig. 2). In this section, we briefly describe some of the mysteries of deep SOM, and then depict how changes with depth in microbial characteristics, the $\mathrm{C}$ to $\mathrm{N}$ ratio of SOM, and temperature regime can be investigated using some of the ideas revealed by aquatic studies, and by advancing microbial models.

We understand very little about what controls the persistence or decay of deep SOM in comparison with our understanding of more surficial processes (Schmidt et al., 2011), though an estimated $21-46 \%$ of global soil C stocks reside 


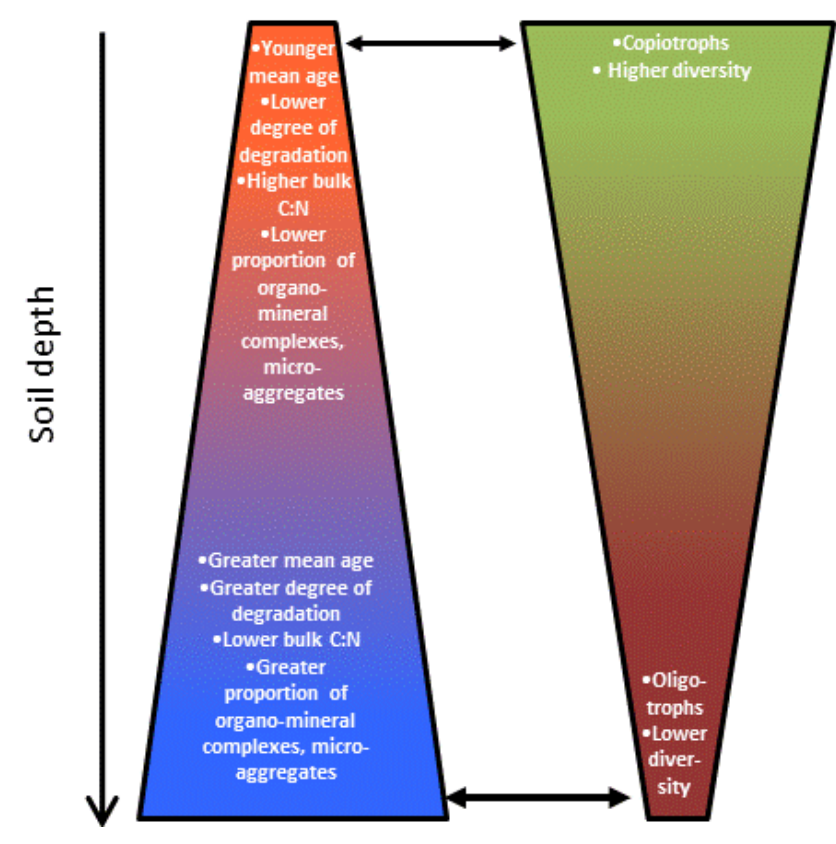

Figure 2. Depiction of parameters describing drivers of SOM decay and retention with depth. Salient physical and chemical features are described on the left, and microbial features on the right. Key features both resulting from and driving patterns of SOM decay are the mean age of SOM and its associated degree of degradation and $\mathrm{C}: \mathrm{N}$ ratio, and the degree to which it forms organo-mineral complexes and micro- vs. macroaggregates. All of these except bulk $\mathrm{C}: \mathrm{N}$ are typically are enhanced with depth. A greater mean residence time is often associated with a greater degree of microbial processing of that material, hence the greater degree of degradation. When coupled with the greater amount of organo-mineral complexes that form with depth, these features drive more energy intensive SOM decay at depth, increasing the activation energy $\left(E_{\mathrm{a}}\right)$ of decay and associated temperature sensitivity of decay. In turn, these physical and chemical changes with depth govern the diversity, physiology, and functional guild of microbial groups in shallow vs. deep soil horizons. The thicker arrow at depth represents likely greater interaction strength in deep soil horizons among energy availability in substrates, temperature sensitivity, and microbial physiology, given the generally greater $E_{\mathrm{a}}$ and lower energy available at depth. Importantly, the microbial community can serve as both an agent of decay and of production of SOM compounds with apparently long residence times; this concept has only recently been explored in the soil literature.

at depths $>100 \mathrm{~cm}$ (Jobbágy and Jackson, 2000). Of course, it is not depth per se that governs SOM persistence or decay, but rather changes with depth in the relative dominance of variables that influence decomposition rates. The predominant state factors (Jenny, 1941) influencing SOM dynamics appear to change below surface horizons: climate becomes less dominant as an influence on SOM transformations with depth, and soil texture appears to assume a greater role (Jóbbagy and Jackson, 2000). In addition, the chemistry of deep SOM is quite different than shallower SOM, with lower $\mathrm{C}: \mathrm{N}$ ratios, a higher abundance of lipids, polysaccharides and $\mathrm{N}$-bearing compounds, enrichment in ${ }^{13} \mathrm{C}$ and ${ }^{15} \mathrm{~N}$, and a greater proportion of apparently slow-to-decay compounds of microbial origin (e.g., Ehleringer et al., 2000; Billings and Richter, 2006; Fröberg et al., 2007; Rumpel and Kögel-Knabner, 2011). These changes in SOM chemistry and abiotic conditions with depth also alter microbial communities, reducing microbial diversity and altering microbial community structure and function (Agnelli et al., 2004; Goberna et al., 2005; Fierer et al., 2003; Will et al., 2010; Gabor et al., 2014; Eilers et al., 2012). Such changes are important not only because they affect SOM decay rates, but also SOM formation; the byproducts of microbial communities appear to comprise a meaningful fraction of OM reservoirs, ranging from 40 to $80 \%$ (Liang et al., 2011; Simpson et al., 2007), and can persist over long timescales (Voroney et al., 1989; Jiao et al., 2010; Six et al., 2006; Miltner et al., 2011; Liang et al., 2011; Grandy and Neff, 2008; Simpson et al., 2007; Hobara et al., 2014). Given that some microbial decomposition byproducts can exhibit relatively slow decay rates and that compounds of microbial origin appear to be preferentially retained in pools of long-lived SOM, we might expect SOM persistence to increase with depth as the dominance of plant relative to microbial inputs decreases (Grandy and Neff, 2008). Our growing appreciation of microbial contributions to SOM and the persistence of some of this material over relatively long timescales prompts calls for experiments designed to reveal how different microbial byproducts from distinct community compositions invite or resist decay (Throckmorton et al., 2012), and for investigations into the relative dominance of microbial vs. plant inputs to deep SOM reservoirs.

Changes in the $\mathrm{C}: \mathrm{N}$ of SOM and soil temperature regime with depth can be connected to the knowledge obtained from aquatic environments about microbial transformations of OM, particularly when we consider interactions between substrate stoichiometry and temperature. For example, the observation that the bioaccessibility of organic C (energy) can govern the ability of microbes to induce decay of slowturnover SOM (Fontaine et al., 2007) is directly relevant to observations of substrate stoichiometry driving microbial biomass, and thus resource requirements, in natural and artificial aquatic environments. Furthermore, bacterial stoichiometry appears to vary in meaningful ways with temperature when nutrients are limiting (Cotner et al., 2006). We thus might predict that when energy (i.e., organic C) is more limiting, as is likely the case deep in a soil profile, where SOM C : $\mathrm{N}$ ratios and plant inputs are relatively low, temperature effects on microbial stoichiometry may be minimal. This prediction, if realized, has important implications for projecting the effect of temperature on deep SOM decay because it suggests that an increase in deep soil temperatures may not induce a large shift in the stoichiometry of resource demand of extant microbial populations, and that microbial responses to temperature will vary with substrate $\mathrm{C}: \mathrm{N}$, and thus with 
depth. The observed importance of substrate and microbial $\mathrm{C}: \mathrm{P}$ and $\mathrm{N}: \mathrm{P}$ ratios as drivers of $\mathrm{OM}$ flow in chemostat studies (Chrzanowski and Kyle, 1996) as temperature varies (Cotner et al., 2006) can also be applied to questions of SOM decay at depth, reminding us that the relative $\mathrm{N}$ vs. $\mathrm{P}$ limitation in terrestrial ecosystems likely will have an influence on each ecosystem's microbial response to temperature. Current models of SOM decay do not incorporate these ideas, but doing so will inform us about an important driver of SOM composition changes with depth: the composition of the material accessed by microbes and transformed into $\mathrm{CO}_{2}$ and other, non-gaseous-phase, microbial byproducts.

We also can use purified substrate-enzyme reaction kinetics (Lehmeier et al., 2013; Min et al., 2014) to formulate additional research questions about increasing SOM persistence with depth, and how destabilization of deep SOM stocks may proceed in a warmer world. For example, $\mathrm{pH}$ optima for exo-enzymatic catalytic rates and well-characterized interactions between $\mathrm{pH}$ and $E_{\mathrm{a}}$ of decay for specific decay reactions (Min et al., 2014) are useful for predicting how these substrate-enzyme reactions may proceed in different soil horizons, if we know how $\mathrm{pH}$ varies with depth in a soil of interest. We also can use changing $\mathrm{C}: \mathrm{N}$ flow ratios as temperature varies (Lehmeier et al., 2013; Min et al., 2014) to predict how microbial resource availability may change with depth. We are far from knowing how $\mathrm{C}$ : $\mathrm{N}$ flow ratios change with temperature in natural environments at any depth, but we at least have a starting point derived from some biogeochemically relevant substrate-enzyme pairings investigated in these works. Examining how divergence from purified reaction kinetics changes with depth in substrate-enzyme reaction rates will provide insight into the varying degree to which physical and chemical protection in the soil matrix, as well as microbial adaptation to temperature, govern depth patterns of SOM decay and retention. This research approach will permit us to address a critical question for understanding deep SOM retention: do deep-profile environmental factors drive greater divergence from intrinsic reaction kinetics than in more shallow horizons, and if so, which ones?

Finally, if a negative relationship between the $E_{\mathrm{a}}$ of decay and $\mathrm{C}: \mathrm{N}$ ratio exists for many soil substrates, as has been hypothesized (Rumpel and Kögel-Knabner, 2011; Billings and Ballantyne, 2013), we can use purified substrate-enzyme reaction kinetics to develop concepts of how microbially available $\mathrm{C}$ and $\mathrm{N}$ may change with depth through a soil profile in a warming climate. This is feasible given known trends in $\mathrm{C}: \mathrm{N}$ and $E_{\mathrm{a}}$ of aggregated substrate decay, which decrease and increase with depth, respectively. It is also feasible to incorporate these concepts into current models of SOM decay: $E_{\mathrm{a}}$ of decay and $\mathrm{C}: \mathrm{N}$ are key features of multiple models currently invoked in the literature. If the temperature sensitivity of decay is greater for many substrates at depth, and many of these substrates possess low $\mathrm{C}: \mathrm{N}$, enzyme kinetics suggest that the availability of $\mathrm{C}$ relative to $\mathrm{N}$ may decline with warming, particularly at depth. Microbes must re- spond to any such change in resource availability, and in so doing can shift community composition and resource allocation, which may influence necromass formation and retention over relatively long time periods (Throckmorton et al., 2012; Nemergut et al., 2014).

Modelers also can take advantage of our existing knowledge of deep SOM characteristics such as low $\mathrm{C}: \mathrm{N}$ ratios and apparently low energy-yielding potential of deep SOC (Fig. 2). Deeper soils also are likely to exhibit preferential sorption of compounds to mineral surfaces (Schrumpf et al., 2013), generating organo-mineral complexes almost impervious to enzymatic attack (Schrumpf et al., 2013; Fontaine et al., 2007; Kögel-Knabner et al., 2008). This, combined with the well-processed nature of deep SOM molecules, results in deep SOM decay requiring a large energy investment by microbes to obtain resources from that decay. Because it is this energy limitation that may be largely responsible for the apparent stability and persistence of deep SOM (Fontaine et al., 2007; Kuzyakov, 2010; Wang et al., 2014), it would be fruitful to use potential energy supply to microbes in varying substrate landscapes as a key feature of microbial models. Studies in controlled aquatic environments where diffusion limitations are small can provide maximum values of energy made available upon decay for such models. Given recent advances in our understanding of linkages between iron reduction and the mobilization of organic $\mathrm{C}$ in soils (Buettner et al., 2014) and a growing understanding of redox features driving diffusive transport of metals (Fimmen et al., 2008), the development of models that account for varying microbial access to SOM given changing forms of soil minerals and diffusive constraints appears to be another low-hanging fruit for the research community. These advances would help us understand how added energy sources can promote enhanced decay of deep SOM (Fontaine et al., 2007), a phenomenon that suggests old SOM is not necessarily intrinsically "recalcitrant" (Kleber, 2010; Kleber et al., 2010).

\section{Conclusions}

1. There has been some effort in the literature to link research that examines natural aquatic, sedimentary, and soil OM transformations (Hedges and Oades, 1997; Billings et al., 2012; Marín-Spiotta et al., 2014). In spite of calls for integration, these disciplines have remained relatively distinct. We emphasize the great utility of employing knowledge from natural aquatic systems to better predict how SOM decay and retention will proceed in the future. Like soils, aquatic systems can reveal how both physical protection and microbially mediated processes govern OM transformations in changing environmental conditions. The concept of the microbial loop in the ocean (Pomeroy, 1974; Azam et al., 1983; Pomeroy et al., 2007) and the observation that microbial byproducts form a great fraction of oceanic OM (Kawasaki 
and Benner, 2006; Kaiser and Benner, 2008; Jiao et al., 2010) pushes soil scientists to test analogous hypotheses in terrestrial systems (Liang et al., 2011). We encourage the further application of empirical observations in aquatic systems in terrestrial soils. In this way, we can develop the nascent concept of soil microbial communities functioning both as decomposers and generators of byproducts with potentially long residence times.

2. With the exception of a few investigators who work in both chemostats and natural aquatic environments (e.g., Elser, 2003), literature describing chemostats is rarely invoked by SOM-focused investigators (Lehmeier et al., 2015). However, chemostats have much to tell us about the influence of resource availability and temperature, for example, on microbial resource demand, resource allocation, and ultimately microbial growth. Understanding how $\mathrm{C}$ is taken up and transformed will help us understand the characteristics of substrates not accessed by microbes and thus features of SOM that persists in soil profiles. This is especially relevant to questions of deep SOM given the increase in SOM mean residence time deep in soil profiles. Chemostats also tell us that microbial growth rate has a direct influence on microbial stoichiometry and specific respiration rate, a phenomenon currently not appreciated by the modeling community. This, in turn, can govern CUE and resource demand - and thus the composition of substrates "left behind" and thus retained in the profile. Chemostat experiments have great potential for understanding SOM dynamics across depth, precisely because they permit manipulation of the very environmental features known to vary with soil depth, such as resource stoichiometry, $E_{\text {a }}$ of decay, and temperature.

3. Purified kinetics of biogeochemically relevant decay reactions provide baseline values to use in models of SOM decay, and differences among known biogeochemical reactions - their raw rates and $E_{\mathrm{a}}$ derived from them - give us a sense of $E_{\mathrm{a}}$ values appropriate for model use. Developing baseline upper values for substrateexo-enzyme reaction kinetics is another important avenue of research for those interested in OM decay and retention. Baseline values derived from purified reaction kinetics allow for the parsing of intrinsic responses to top-down drivers of decay such as temperature from other soil-specific factors that may change with the environment.

4. There are important and underexplored avenues for modelers who focus on SOM transformations in response to changing climate, and within soil profiles across depth. For example, modelers who attempt to use soil physics and diffusive properties of enzymes and substrates to better predict OM transformations can expand their efforts to explicitly model shallow versus deep SOM. By altering diffusive parameters to better reflect the differences in relative abundances of macro vs. microaggregate structure across soil depth, and the different degrees of tortuosity throughout a soil profile, we can gain a sense of the importance of these features as drivers of SOM protection at depth. Scaling approaches will be critical for extending profile-scale dynamics to scales relevant for Earth system models. Modelers also can use information from some natural aquatic environments and chemostats to better understand how microbial stoichiometry, resource access, elemental cell content, and specific respiration rates change with environmental conditions. Though absolute values of these parameters from chemostats are likely not appropriate for use in modeling soil profiles, chemostat values provide at least qualitative indications of how these parameters may change with environmental conditions, including those that vary with depth.

Acknowledgements. The authors thank Johan Six for his encouragement in writing this paper, Mitch Sellers for assistance organizing the references, and two anonymous reviewers, whose input improved the manuscript. This work was partially supported via National Science Foundation grants DEB-0950095 and EAR1331846. We also are grateful for discussions among members of the KU Center for Metagenomic Microbial Community Analyses.

Edited by: K. Denef

\section{References}

Agnelli, A., Ascher, J., Corti, G., Ceccherini, M. T., Nannipieri, P., and Pietramellara, J.: Distribution of microbial communities in a forest soil profile investigated by microbial biomass, soil respiration and DGGE of total and extracellular DNA, Soil Biol. Biochem., 36, 859-868, 2004.

Allison, S. D.: Cheaters, diffusion and nutrients constrain decomposition by microbial enzymes in spatially structured environments, Ecol. Lett., 8, 626-635, 2005.

Allison, S. D.: A trait-based approach for modelling microbial litter decomposition, Ecol. Lett., 15, 1058-1070, 2012.

Allison, S. D., Wallenstein, M. D., and Bradford, M. A.: Soil-carbon response to warming dependent on microbial physiology, Nat. Geosci., 3, 336-340, 2010.

Amado, A. M., Meirelles-Pereira, F., Vidal, L. O., Sarmento, H., Suhett, A. L., Farjalla, V. F., Cotner, J., and Roland, F.: Tropical freshwater ecosystems have lower bacterial growth efficiency than temperate ones, Front. Microbiol., 4, 1-8, 2013.

Amutha, B., Khire, J. M., and Khan, M. I.: Characterization of a novel exo-N-acetyl- $\beta$-D-glucosaminidase from the thermotolerant Bacillus sp. NCIM 5120, Biochim. Biophys. Acta, 1425, 300-310, 1998.

Azam, F., Fenchel, T., Field, J. G., Gray, J. S., Meyer-Reil, L. A., and Thingstad, F.: The ecological role of water-column microbes in the sea, Mar. Ecol. Prog. Ser., 10, 257-263, 1983. 
Baldrian, P. and López-Mondéjar, R.: Microbial genomics, transcriptomics and proteomics: new discoveries in decomposition research using complementary methods, Appl. Microbiol. Biot., 98, 1531-1537, 2014.

Ballantyne IV, F. and Billings, S. A.: Linking microbial resource allocation to exoenzymes, biomass stoichiometry, and soil respiration, Ecol. Lett., in revision, 2015.

Barta, J., Slajsova, P., Tahovska, K., Picek, T., and Santruckova, H.: Different temperature sensitivity and kinetics of soil enzymes indicate seasonal shifts in $\mathrm{C}, \mathrm{N}$ and $\mathrm{P}$ nutrient stoichiometry in acid forest soil, Biogeochemistry, 117, 525-537, 2014.

Battin, T. J., Luyssaert, S., Kaplan, L. A., Aufdenkampe, A. K., Richter, A., and Tranvik, L. J.: The boundless carbon cycle, Nat. Geosci., 2, 598-600, 2009.

Billings, S. A. and Ballantyne, F.: How interactions between microbial resource demands, soil organic matter stoichiometry, and substrate reactivity determine the direction and magnitude of soil respiratory responses to warming, Glob. Change Biol., 19, 90$102,2013$.

Billings, S. A. and Richter, D. D.: Changes in stable isotopic signatures of soil nitrogen and carbon during 40 years of forest development, Oecologia, 148, 325-333, 2006.

Billings, S. A. and Tiemann, L. K.: Warming-induced enhancement of soil $\mathrm{N}_{2} \mathrm{O}$ efflux linked to distinct response times of genes driving $\mathrm{N}_{2} \mathrm{O}$ production and consumption, Biogeochemistry, 119, 371-386, 2014.

Billings, S. A., Ziegler, S. E., Schlesinger, W. H., Benner, R., and Richter, D. D.: Predicting carbon cycle feedbacks to climate: integrating the right tools for the job, EOS, 93, 188-189, 2012.

Blair, N., Leu, A., Muñoz, E., Olsen, J., Kwong, E., and Des Marals, D.: Carbon isotopic fractionation in heterotrophic microbial metabolism, Appl. Environ. Microb., 50, 996-1001, 1985.

Bolker, B. and Pacala, S. W.: Using moment equations to understand stochastically driven spatial pattern formation in ecological systems, Theor. Popul. Biol., 52, 179-197, 1997.

Bosatta, E. and Ågren, G. I.: Soil organic matter quality interpreted thermodynamically, Soil Biol. Biochem., 31, 1889-1891, 1999.

Bradford, M. A.: Thermal adaptation of decomposer communities in warming soils, Front. Microbiol., 4, 1-16, 2013.

Buettner, S. W., Kramer, M. G., Chadwick, O. A., and Thompson, A.: Mobilization of colloidal carbon during iron reduction in basaltic soils, Geoderma, 221, 139-145, 2014.

Cheng, W., Parton, W. J., Gonzalez-Meler, M. A., Phillips, R., Asao, S., McNickle, G. G., Brzostek, E., and Jastrow, J. D.: Synthesis and modeling perspectives of rhizosphere priming, New Phytol., 201, 31-44, 2014.

Chrzanowski, T. H. and Kyle, M.: Ratios of carbon, nitrogen and phosphorus in Pseudornonas fluorescens as a model for bacterial element ratios and nutrient regeneration, Aquat. Microb. Ecol., 10, 115-122, 1996.

Chrzanowski, T. H. and Grover, J. P.: Element content of Pseudomonas fluorescens varies with growth rate and temperature: A replicated chemostat study addressing ecological stoichiometry, Limnol. Oceanogr., 53, 1242-1251, 2008.

Cleveland, C. C. and Liptzin, D.: C : N : P Stoichiometry in Soil: Is There a "Redfield Ratio: for the Microbial Biomass?, Biogeochemistry, 85, 235-252, 2007.

Conant, R. T., Ryan, M. G., Ågren, G. I., Birge, H. E., Davidson, E. A., Eliasson, P. E., Evans, S. E., Frey, S. D., Giardina, C. P.,
Hopkins, F. M., Hyvönen, R., Kirschbaum, M. U. F., Lavalle, J. M., Leifeld, J., Parton, W. J., Steinweg, J. M., Wallenstein, M. D., Martin Wetterstedt, J. Å., and Bradford, M. A.: Temperature and soil organic matter decomposition rates - synthesis of current knowledge and a way forward, Glob. Change Biol., 7, 3392-3404, 2011.

Cotner, J. B., Makino, W., and Biddanda, B. A.: Temperature Affects Stoichiometry and Biochemical Composition of Escherichia coli, Microbial Ecol., 52, 26-33, 2006.

Craine, J. M., Fierer, N., and McLauchlan, K. K.: Widespread coupling between the rate and temperature sensitivity of organic matter decay, Nat. Geosci., 3, 854-857, 2010.

Dauner, M., Storni, T., and Sauer, W.: Bacillus subtillis metabolism and energetics in carbon-limited and excess-carbon chemostat culture, J. Bacteriol., 183, 7308-7317, 2001.

Davidson, E. A. and Janssens, I. A.: Temperature sensitivity of soil carbon decomposition and feedbacks to climate change, Nature, 440, 165-173, 2006.

Davidson, E. A., Samanta, D., Caramori, S. S., and Savage, K.: The Dual Arrhenius and Michaelis-Menten kinetics model for decomposition of soil organic matter at hourly to seasonal time scales, Glob. Change Biol., 18, 371-384, 2012.

Del Giorgio, P. A. and Cole, J. J.: Bacterial growth efficiency in natural aquatic systems, Annu. Rev. Ecol. Syst., 29, 503-541, 1998.

Dijkstra, P., Thomas, S. C., Heinrich, P. L., Koch, G. W., Schwartz, E., and Hungate, B. A.: Effect of temperature on metabolic activity of intact microbial communities: Evidence for altered metabolic pathway activity but not for increased maintenance respiration and reduced carbon use efficiency, Soil Biol. Biochem., 43, 2023-2031, 2011.

Droop, M. R.: The nutrient status of algal cells in continuous culture, J. Mar. Biol. Assoc., 54, 825-855, 1974.

Dungait, J. A. J., Hopkins, D. W., and Gregory, A. S.: Soil organic matter turnover is governed by accessibility not recalcitrance, Glob. Change Biol., 18, 1781-1796, 2012.

Durrett, R. and Levin, S.: The importance of being discrete (and spatial), Theor. Popul. Biol., 46, 363-394, 1994.

Ehleringer, J. R., Buchmann, N., and Flanagan, L. B.: Carbon isotope ratios in belowground carbon cycle processes, Ecol. Appl., 10, 412-422, 2000.

Eilers, K. G., Debenport, S., Anderson, S., and Fierer, N.: Digging deeper to find unique microbial communities: the strong effect of depth on the structure of bacterial and archaeal communities in soil, Soil Biol. Biochem., 50, 58-65, 2012.

Eivazi, F. and Tabatabai, M. A.: Glucosidases and galacotisdases in soils, Soil Biol. Biochem., 20, 601-606, 1988.

Elser, J. J., Sterner, R. W., Gorokhova, E., Fagan, W. F., Markow, T. A., Cotner, J. B., Harrison, J. F., Hobbie, S. E., Odell, G. M., and Weider, L. J.: Biological stoichiometry from genes to ecosystems, Ecol. Lett., 3, 540-550, 2000.

Elser, J. J., Acharya, K., Kyle, M., Cotner, J., Makino, W., Markow, T., Watts, T., Hobbie, S., Fagan, W., Schade, J., Hood, J., and Sterner, R. W.: Growth rate-stoichiometry couplings in diverse biota, Ecol. Lett., 6, 936-943, 2003.

Evans, S. E. and Wallenstein, M. D.: Soil microbial community response to drying and rewetting stress: does historical precipitation regime matter?, Biogeochemistry, 109, 101-116, 2012. 
Ferenci, T.: Regulation by nutrient limitation, Curr. Opin. Microbiol., 2, 208-213, 1999.

Ferenci, T.: Bacterial physiology, regulation and mutational adaptation in a chemostat environment, Adv. Microb. Physiol., 53, 169-230, 2008.

Fierer, N., Schimel, J. P., and Holden, P. A.: Variations in microbial community composition through two soil depth profiles, Soil Biol. Biochem., 35, 167-176, 2003.

Fimmen, R. L., Richter, D. de B., Vasudevan, D., Williams, M. A., and West, L. T.: Rhizogenic Fe-C redox cycling: a hypothetical biogeochemical mechanism that drives crustal weathering in upland soils, Biogeochemistry., 87, 127-141, 2008.

Flury, S. and Gessner, M. O.: Effects of experimental warming and nitrogen enrichment onleaf and litter chemistry of a wetland grass, Phragmites australis, Basic Appl. Ecol., 15, 219-228, 2014.

Fontaine, S., Barot, S., Barré, P., Bdioui, N., Mary, B., and Rumpel, C.: Stability of organic carbon in deep soil layers controlled by fresh carbon supply, Nature, 450, 277-281, 2007.

Frey, S. D., Lee, J., Melillo, J. M., and Six, J.: The temperature response of soil microbial efficiency and its feedback to climate, Nat. Clim. Change, 3, 395-398, 2013.

Fröberg, M., Jardine, P. M., Hanson, P. J., Swanston, C. W., Todd, D. E., Tarver, J. R., and Garten Jr., C. T.: Low dissolved organic carbon input from fresh litter to deep mineral soils, Soil Sci. Soc. Am. J., 71, 347-354, 2007.

Gabor, R. S., Eilers, K., McKnight, D. M., Fierer, N., and Anderson, S. P.: From the litter layer to the saprolite: Chemical changes in water-soluble soil organic matter and their correlation to microbial community composition, Soil Biol. Biochem., 68, 166-176, 2014.

Geider, R. J. and La Roche, J.: Redfield revisited: variability of $\mathrm{C}: \mathrm{N}: \mathrm{P}$ in marine microalgae and its biochemical basis, Eur. J. Phycol., 37, 1-17, 2002.

German, D. P., Marcelo, K. R. B., Stone, M. M., Allison, S. D.: The Michaelis-Menten kinetics of soil extracellular enzymes in response to temperature: a cross-latitudinal study, Glob. Change Biol., 18, 1468-1479, 2012.

Goberna, M., Insam, H., Klammer, S., Pascual, J. A., and Sanchez, J.: Microbial community structure at different depths in disturbed and undisturbed semiarid Mediterranean forest soils, Microb. Ecol., 50, 315-326, 2005.

Grandy, A. S. and Neff, J. C.: Molecular C dynamics downstream: the biochemical decomposition sequence and its impact on soil organic matter structure and function, Sci. Total Environ., 404, 297-307, 2008.

Gülez, G., Dechesne, A., Workman, C. T., and Smets, B. F.: Transcriptome dynamics of Pseudomonas putida KT2440 under water stress, Appl. Environ. Microb., 78, 676-683, 2012.

Hall, E. K. and Cotner, J. B.: Interactive effect of temperature and resources on carbon cycling by freshwater bacterioplankton communities, Aquat. Microb. Ecol., 49, 35-45, 2007.

Hall, E. K., Neuhauser, C., and Cotner, J. B.: Toward a mechanistic understanding of how natural bacterial communities respond to changes in temperature in aquatic ecosystems, ISME J., 2, 471481,2008

Hebly, M., de Ridder, D., de Hulster, E. A., de la Torre Cortes, P., Pronk, J. T., and Daran-Lapujade, P.: Physiological and transcriptional responses of anaerobic chemostat cultures of Sac- charomyces cerevisiae subjected to diurnal temperature cycles, Appl. Environ. Microb., 80, 4433-4449, 2014.

Hedges, J. I. and Oades, J. M.: Comparative organic geochemistries of soils and marine sediments, Org. Geochem., 27, 319-361, 1997.

Henn, M. R. and Chapela, I. H.: Differential C isotope discrimination by fungi during decomposition of $\mathrm{C}_{3}$ - and $\mathrm{C}_{4}$-derived sucrose, Appl. Environ. Microb., 66, 4180-4186, 2000.

Hessen, D. O., Elser, J. J., Sterner, R. W., and Urabe, J.: Ecological stoichiometry: An elementary approach using basic principles, Limnol. Oceanogr., 58, 2219-2236, 2013.

Hobara, S., Osono, T., Hirose, D., Noro, K., Mitsuru, H., and Benner, R.: The roles of microorganisms in litter decomposition and soil formation, Biogeochemistry, 118, 471-486, 2014.

Howe, A. C., Jansson, J. K., Malfatti, S. A., Tringe, S. G., Tiedje, J. M., and Brown, C. T.: Tackling soil diversity with the assembly of large, complex metagenomes, P. Natl. Acad. Sci., 111, 49044909, 2014.

Hua, Q., Yang, C., Oshima, T., Mori, H., and Shimizu, K.: Analysis of gene expression in Escherichia coli in response to changes of growth-limiting nutrient in chemostat cultures, Appl. Environ. Microb., 70, 2354-2366, 2004.

Jenny, H.: Factors of Soil Formation. A System of Quantitative Pedology, McGraw Hill Book Company, New York, NY, USA, 1941.

Jiao, N., Herndl, G. H., Hansell, D. A., Benner, R., Kattner, G., Wilhelm, S. W., Kirchman, D. L., Weinbauer, M. G., Luo, T., Chen, F., and Azam, F.: Microbial production of recalcitrant dissolved organic matter: long-term carbon storage in the global ocean, Nat. Rev. Microbiol., 8, 593-599, 2010.

Jobbágy, E. and Jackson, R. B.: The vertical distribution of soil organic carbon and its relation ot climate and vegetation, Ecol. Appl., 10, 423-436, 2000.

Jordan, T., Ashley, G. M., Barton, M. D., Burges, S. J., Farley, K. A., Freeman, K. H., Jeanloz, R., Marshall, C. R., Orcutt, J. A., Richter, F. M., Royden, L. H., Scholz, C. H., Tyler, N., and Wilding, L. P.: Basic Research Opportunities in Earth Science, National Academy Press, Washington, D.C., 2001.

Kaiser, K. and Benner, R.: Major bacterial contribution to the ocean reservoir of detrital organic carbon and nitrogen, Limnol. Oceanogr., 53, 99-112, 2008.

Kawasaki, N. and Benner, R.: Bacterial release of dissolved organic matter during cell growth and decline: molecular origin and composition, Limnol. Oceanogr., 51, 2170-2180, 2006.

Kayser, A., Weber, J., Hecht, V., and Rinas, U.: Metabolic flux analysis of Escherichia coli in glucose-limited continuous culture. I. Growth-rate dependent metabolic efficiency at steady state, Microbiol-SGM, 151, 693-706, 2005.

Khalili, B., Nourbakhsh, F., Nili, N., Khademi, H., and Sharifnabi, B.: Diversity of soil cellulase isoenzymes is associated with soil cellulase kinetic and thermodynamic parameters, Soil Biol. Biochem., 43, 1639-1648, 2011.

Kirschbaum, M. U. F.: The temperature dependence of soil organic matter decomposition, and the effect of global warming on soil organic storage, Soil Biol. Biochem., 27, 753-760, 1995.

Klausmeier, C. A., Litchman, E., and Levin, S. A.: A model of flexible uptake of two essential resources, J. Theor. Biol., 246, 278289, 2007. 
Kleber, M.: What is recalcitrant soil organic matter?, Environ. Chem., 7, 320-332, 2010.

Kleber, M., Nico, P. S., Plante, A., Filley, T., Kramer, M., Swanston, C., and Sollins, P.: Old and stable soil organic matter is not necessarily chemically recalcitrant: implications for modeling concepts and temperature sensitivity, Glob. Change Biol., 17, 10971107, doi:10.1111/j.1365-2486.2010.02278.x, 2010.

Kögel-Knabner, I., Ekschmitt, K., Flessa, H., Guggenberger, G., Matzner, E., Marschner, B., and von Lutzow, M.: An integrative approach of organic matter stabilization in temperate soils: Linking chemistry, physics, and biology, J. Plant Nutr. Soil Sc., 171, 5-13, 2008.

Kuzyakov, Y.: Priming effects: interactions between living and dead organic matter, Soil Biol. Biochem., 42, 1363-1371, 2010.

Laganiere, J., Podrebarac, F., Billings, S. A., Edwards, K. A., and Ziegler, S. E.: A warmer climate reduces biological reactivity without increasing the temperature sensitivity of $\mathrm{CO}_{2}$ losses in boreal forest soils, Soil Biol. Biochem., 84, 177-188, 2015.

Larsson, C., von Stockar, U., Marison, I., and Gustafsson, L.: Growth and metabolism of Saccharomyces cerevisiae in chemostat cultures under carbon-, nitrogen-, or carbon- and nitrogenlimiting conditions, J. Bacteriol., 175, 4809-4816, 1993.

Lehmeier, C. A., Min, K., Niehues, N. D., Ballantyne IV, F., and Billings, S. A.: Temperature-mediated changes of exoenzymesubstrate reaction rates and their consequences for the carbon to nitrogen flow ratio of liberated resources, Soil Biol. Biochem., 57, 374-382, 2013.

Lehmeier, C. A., Ballantyne IV, F., Min, K., and Billings, S. A.: Temperature-mediated changes in microbial carbon use efficiency and ${ }^{13} \mathrm{C}$ discrimination, submitted, 2015.

Li, J., Ziegler, S., Lane, C. S., and Billings, S. A.: Warmingenhanced preferential microbial mineralization of humified boreal forest soil organic matter: Interpretation of soil profiles along a climate transect using laboratory incubations, J. Geophys. Res., 117, G02008, doi:10.1029/2011JG001769, 2012.

Liang, C., Cheng, G., Wixon, D. L., and Balser, T. C.: An Absorbing Markov Chain approach to understanding the microbial role in soil carbon stabilization, Biogeochemistry, 106, 303-309, 2011.

Luo, C., Rodriguez-R, L. M., Johnston, E. R., Wu, L., Cheng, L., Xue, K., and Konstantinidis, K. T.: Soil microbial community responses to a decade of warming as revealed by comparative metagenomics, Appl. Environ. Microb., 80, 1777-1786, 2014.

Makino, W., Cotner, J. B., Sterner, R. W., and Elser, J. J.: Are bacteria more like plants or animals? Growth rate and resource dependence of bacterial $\mathrm{C}: \mathrm{N}: \mathrm{P}$ stoichiometry, Funct. Ecol., 17, 121-130, 2003.

Manzoni, S. and Porporato, A.: Soil carbon and nitrogen mineralization: Theory and models across scales, Soil Biol. Biochem., 41, 1355-1379, 2009.

Manzoni, S., Taylor, P., Richter, A., Porporato, A., and Ågren, G. I.: Environmental and stoichiometric controls on microbial carbon-use efficiency in soils, New Phytol., 196, 79-91, doi:10.1111/j.1469-8137.2012.04225.x, 2012a.

Manzoni, S., Schimel, J. P., and Porporato, A.: Responses of soil microbial communities to water stress: results from a meta-analysis, Ecology, 93, 930-938, 2012b.

Manzoni, S., Schaeffer, S. M., Katul, G., Porporato, A., and Schimel, J. P.: A theoretical analysis of microbial eco- physiological and diffusion limitations to carbon cycling in drying soils, Soil Biol. Biochem., 73, 69-83, 2014.

Marín-Spiotta, E., Gruley, K. E., Crawford, J., Atkinson, E. E., Miesel, J. R., Greene, S., Cardona-Correa, C., and Spencer, R. G. M.: Paradigm shifts in soil organic matter research affect interpretations of aquatic carbon cycling: transcending disciplinary and ecosystem boundaries, Biogeochemistry, 117, 279297, 2014.

Masse, D., Cambier, C., Bauman, A., Sall, S., Assigbetse, K., and Chotte, J.-L.: Mior: an individual-based model for simulating the spatial patterns of soil organic matter microbial decomposition, Eur. J. Soil Sci., 58, 1127-1135, 2007.

Miller, A. W., Belfort, C., Kerr, E. O., and Dunham, M. J.: Design and Use of Multiplexed Chemostat Arrays, J. Visualized Exp., 72, 1-6, 2013.

Miltner, A., Bombach, P., Schmidt-Brücken, B., and Kästner, M.: SOM genesis: microbial biomass as a significant source, Biogeochemistry, 111, 41-55, 2011.

Min, K., Lehmeier, C. A., Ballantyne, F., Tatarko, A., and Billings, S. A.: Differential effects of $\mathrm{pH}$ on temperature sensitivity of organic carbon and nitrogen decay, Soil Biol. Biochem., 76, 193200, 2014.

Moorhead, D. L., Lashermes, G., Sinsabaugh, R. L.: A theoretical model of $\mathrm{C}$ - and $\mathrm{N}$-acquiring exoenzyme activities, which balances microbial demands during decomposition, Soil Biol. Biochem., 53, 133-141, 2012.

Monod, J.: La technique de culture continue; theorie et application, Ann. Inst. Pasteur, 79, 390-410, 1950.

Moyano, F. E., Manzoni, S., and Chenu, C.: Responses of soil heterotrophic respiration to moisture availability: An exploration of processes and models, Soil Biol. Biochem., 59, 72-85, 2013.

Nanchen, A., Schicker, A., and Sauer, U.: Nonlinear dependency of intracellular fluxes on growth rate in miniaturized continuous cultures of Escherichia coli, Appl. Environ. Microb., 72, 1164$1172,2006$.

Nemergut, D. R., Shade, A., and Violle, C.: When where, and how does microbial community composition matter?, Front. Microbiol., 5, 1-3, doi:10.3389/fmicb.2014.00497, 2014.

Ofek-Lalzar, M., Sela, N., Goldman-Voronov, M., Green, S. J., Hadar, Y., Minz, D.: Niche and host-associated functional signatures of the root surface microbiome, Nat. Comm., 5, 4950, doi:10.1038/ncomms5950, 2014.

Ottesen, E. A., Young, C. R., Gifford, S. M., Eppley, J. M., Marin III, R., Schuster, S. C., Scholin, C. A., and DeLong, E. F.: Multispecies diel transcriptional oscillations in open ocean heterotrophic bacterial assemblages, Science, 345, 207-212, 2014.

Parham, J. A. and Deng, S. P.: Detection, quantification and characterization of $\beta$-glucosaminidase activity in soil, Soil Biol Biochem., 33, 1183-1190, 2000.

Pataki, D. E.: Emerging topics in stable isotope ecology: are there isotope effects in plant respiration?, New Phytol., 167, 321-323, 2005.

Payot, S., Guedon, E., Cailliez, C., Gelhaye, E., and Petitdemange, H.: Metabolism of cellobiose by Clostribium celluloyticurn growing in continuous culture: evidence for decreased nadh reoxiation as a factor limiting growth, Microbiol., 144, 375-384, 1998.

Pomeroy, L. R.: The ocean's food web, a changing paradigm, Bioscience, 24, 499-504, 1974. 
Pomeroy, L. R., Williams, P. J., Azam, F., and Hobbie, J. E.: The microbial loop, Oceanography, 20, 28-33, 2007.

Prestat, E., David, M. M., Tas, N., Lamendella, R., Dvornik, J., Mackelprang, R., Myrold, D. D., Jumpponen, A., Tringe, S. C., Holman, E., Mavromatis, K., and Jansson, J. K.: FOAM (Functional Ontology Assignments for Metagenomes): a Hidden Markov Model (HMM) database with environmental focus, $\mathrm{Nu}-$ cleic Acids Res., 42, e145, doi:10.1093/nar/gku702, 2014.

Rhee, G.-Y. and Gotham, I. J.: The effect of environmental factors on phytoplankton growth: Temperature and the interactions of temperature with nutrient limitation, Limnol. Oceanogr., 26, 635-648, 1981.

Richter, D. and Billings, S. A.: “One Physical System”: Tansley's Ecosystem as Earth's Critical Zone, New Phytol., online first, doi:10.1111/nph.13338, 2015.

Rumpel, C. and Kögel-Knabner, I.: Deep soil organic matter-a key but poorly understood component of terrestrial C cycle, Plant Soil, 338, 143-158, 2011.

Scheibe, T. D., Mahadevan, R., Fang, Y., Garg, S., Lon, P. E., and Lovley, D. R.: Coupling a genome-scale metabolic model with a reactive transport model to describe in situ uranium bioremediation, Microb. Biotech., 2, 274-286, 2009.

Schimel, J. P. and Schaeffer, S. M.: Microbial control over carbon cycling in soil, Front. Microbiol., 3, 1-11, 2012.

Schimel, J. P. and Weintraub, M. N.: The implication of exoenzyme activity on microbial carbon and nitrogen limitation in soil: a theoretical model, Soil Biol. Biochem., 35, 549-563, 2002.

Schmidt, M. W. I., Torn, M. S., Abiven, S. A., Dittmar, T., Guggenberger, G., Janssens, I. A., Kleber, M., Kögel-Knabner, I., Lehmann, J., Manning, D. A. C., Nannipieri, P., Rasse, D. P., Weiner, S., and Trumbore, S. E.: Persistence of soil organic matter as an ecosystem property, Nature, 478, 49-56, 2011.

Schrumpf, M., Kaiser, K., Guggenberger, G., Persson, T., KögelKnabner, I., and Schulze, E.-D.: Storage and stability of organic carbon in soils as related to depth, occlusion within aggregates, and attachment to minerals, Biogeosciences, 10, 16751691, doi:10.5194/bg-10-1675-2013, 2013.

Sierra, C.: Temperature sensitivity of organic matter decomposition in the Arrhenius equation: some theoretical considerations, Biogeochemistry, 108, 1-15, 2012.

Simonds, S., Grover, J. P., and Chrzanowski, T. H.: Element content of Ochromonas danica: a replicated chemostat study controlling the growth rate and temperature, FEMS Microb. Ecol., 74, 346$352,2010$.

Simpson, A. J., Simpson, M. J., Smith, E., Kelleher, B. P.: Microbially derived inputs to soil organic matter: are current estimates too low?, Environ. Sci. Technol., 41, 8070-8076, 2007.

Sinsabaugh, R. L., Follstad Shah, J. J., Hill, B. H., and Elonen, C. M.: Ecoenzymatic stoichiometry of stream sediments with comparison to terrestrial soils, Biogeochemistry, 111, 455-467, 2012.

Sinsabaugh, R. L., Manzoni, S., Moorhead, D. L., and Richter, A.: Carbon use efficiency of microbial communities: stoichiometry, methodology and modelling, Ecol. Lett., 16, 930-939, 2013.

Six, J. and Paustian, K.: Aggregate-associated soil organic matter as an ecosystem property and a measurement tool, Soil Biol. Biochem., 68, A4-A9, doi:10.1016/j.soilbio.2013.06.014, 2013.

Six, J., Frey, S. D., Thiet, R. K., and Batten, K. M.: Bacterial and fungal contributions to carbon sequestration in agroecosystems, Soil Sci. Soc. Am. J., 70, 555-569, 2006.
Steinweg, J. M., Jagadamma, S., Frerichs, J., and Mayes, M. A.: Activation energy of extracellular enzymes in soils from different biomes, PLos One, 8, e59943, doi:10.1371/journal.pone.0059943, 2013.

Sterner, R. W., Anderson, T., Elser, J. J., Hessen, D. O., Hood, J. M., McCauley, E., and Urabe, J.: Scale-dependent carbon : nitrogen : phosphorus seston stoichiometry in marine and freshwaters, Limnol. Oceanogr., 53, 1169-1180, 2008.

Stets, E. G. and Cotner, J. B.: The influence of dissolved organic carbon on bacterial phosphorus uptake and bacteria-phytoplankton dynamics in two Minnesota lakes, Limnol. Oceanogr., 53, 137147, 2008.

Stone, E. L. and Kalisz, P. J.: On the maximum extent of tree roots, Forest Ecol. Manag., 46, 59-102, 1991.

Tang, J. and Riley, W. J.: Weaker soil carbon-climate feedbacks resulting from microbial and abiotic interactions, Nat. Clim. Change, 5, 56-60, doi:10.1038/NCLIMATE2438, 2015.

Tang, Y. J., Martin, H. G., Myers, S., Rodriguez, S., Baidoo, E. E. K., and Keasling, J. D.: Advances in analysis of microbial metabolic fluxes via ${ }^{13} \mathrm{C}$ isotopic labeling, Mass Spectrom. Rev., 28, 362-375, 2009.

Throckmorton, H. M., Bird, J. A., Dane, L., Firestone, M. K., and Horwath, W. R.: The source of microbial C has little impact on soil organic matter stabilization in forest ecosystems, Ecol. Lett., 15, 1257-1265, 2012.

Tiemann, L. K. and Billings, S. A.: Changes in variability of soil moisture alter microbial community $\mathrm{C}$ and $\mathrm{N}$ resource use, Soil Biol. Biochem., 43, 1837-1847, 2011a.

Tiemann, L. K. and Billings, S. A.: Indirect effects of nitrogen amendments on organic substrate quality increase enzymatic activity driving decomposition in a mesic grassland, Ecosystems, 14, 234-247, 2011b.

Trasar-Cepeda, C., Gil-Sotres, F., and Leirós, M. C.: Thermodynamic parameters of enzymes in grassland soils from Galicia, NW Spain, Soil Biol. Biochem., 39, 311-319, 2007.

Trumbore, S.: Radiocarbon and Soil Carbon Dynamics, Annu. Rev. Earth Planet. Sc., 37, 47-66, 2009.

Vetter, Y. A., Deming, J. W., Jumars, P. A., and Krieger-Brockett, B. B.: A predictive model of bacterial foraging by means of freely released extracellular enzymes, Microbiol. Ecol., 36, 7592, 1998.

Voroney, R. P., Paul, E. A., and Anderson, D. W.: Decomposition of wheat straw and stabilization of microbial products, Can. J. Soil Sci., 69, 63-77, 1989.

Wagai, R., Kishimoto-mo, A. W., Yonemura, S., Shirato, Y., Hiradate, S., and Yagasaki, Y.: Linking temperature sensitivity of soil organic matter decomposition to its molecular structure, accessibility, and microbial physiology, Glob. Change Biol., 19, 1114$1125,2013$.

Wang, X., Liu, L., Piao, S., Janssens, I. A., Tang, J., Liu, W., Chi, Y., Wang, J., and Xu, S.: Soil respiration under climate warming: differential response of heterotrophic and autotrophic respiration, Glob. Change Biol., 20, 3229-3237, 2014.

Wieder, W. R., Bonan, G. B., and Allison, S. D.: Global soil carbon projections are improved by modelling microbial processes, Nat. Clim. Change, 3, 909-912, 2013.

Wieder, W. R., Grandy, A. S., Kallenbach, C. M., and Bonan, G. B.: Integrating microbial physiology and physio-chemical principles in soils with the MIcrobial-MIneral Carbon Stabilization (MIM- 
ICS) model, Biogeosciences, 11, 3899-3917, doi:10.5194/bg11-3899-2014, 2014.

Will, C., Thürmer, A., Wollherr, A., Nacke, H., Herold, N., Schrumpf, M., Gutknecht, J., Wubet, T., Buscot, F., and Daniel, R.: Horizon-specific bacterial community composition of German grassland soils, as revealed by pyrosequencing-based analysis of 16S rRNA genes, Appl. Environ. Microb., 76, 6751-6759, 2010.
Ziegler, S. E., White, P. M., Wolf, D. C., and Thoma, G. J.: Tracking the fate and recycling of ${ }^{13} \mathrm{C}$-labeled glucose in soil, Soil Sci., 170, 767-778, 2005. 